\title{
Investigating the Effect of Hydrophobic Additives in Moisture Damage Reduction of Asphalt Mixtures
}

\author{
Gholam Hossein Hamedi ${ }^{1 *}$, Amir Shabani², Yasaman Safargar ${ }^{3}$ \\ 1 Department of Civil Engineering, Faculty of Engineering, University of Guilan, P. O. B. 3756, Rasht, Iran \\ 2 Department of Civil and Architectural Engineering, Faulty of Engineering, KTH Royal Institute of Technology, P. O. B. 1031, \\ Stockholm, Sweden \\ ${ }^{3}$ Department of Civil Engineering, Faculty of Engineering, Shahrood University of Technology, P. O. B. 316, Shahrood, Iran \\ *Corresponding author, e-mail: hamedi@guilan.ac.ir
}

Received: 18 December 2019, Accepted: 15 April 2020, Published online: 14 May 2020

\begin{abstract}
In order to increase the life of the asphalt mixture and reduce the cost of the pavement life cycle, methods must be provided to improve the quality. Accordingly, the effects of aggregate surface coating with hydrophobic material in order to modify the aggregate mixture's polar properties and reduce its hydrophilic properties are investigated. To this end, limestone and granite aggregates, 60-70 bitumen, and Two types of additives were used as the primary materials for the construction of asphalt mixtures. Thermodynamic concepts with cyclic loading have been used to evaluate the effects of these additives. The results obtained in this study indicate that the hydrophobic coating on the aggregate surface has increased the acidic components and decreased the alkaline components of the surface free energy for both types of aggregates. These changes will increase the bitumen-aggregate adhesion and make a better coating of bitumen on the aggregate surface. The results based on thermodynamic concepts suggest that the aggregate surface coating has reduced the system's separation energy and the desire for stripping. The results of the dynamic modulus in wet to dry conditions also approve this outcome. The combination of thermodynamic concepts and the cyclic loading results show that the coating on the aggregate surface has reduced the aggregate's stripping from bitumen. It is also obvious that the samples made with granite aggregates, which have acidic properties, are prone to moisture damage and have a higher tendency to strip.
\end{abstract}

\section{Keywords}

asphalt mixtures, moisture damage, hydrophilicity, surface free energy, dynamic modulus, aggregate surface coating

\section{Introduction}

Moisture damage is defined as the loss of resistance and durability in asphalt mixtures due to the influence of moisture. This type of damage can be divided into two main processes: adhesion loss, and continuity loss [1]. The bitumen layer is separated from the surface of the aggregate due to the aggregate's higher propensity to absorb water than bitumen. Loss of continuity is due to the changing bitumen's characteristics as a result of the interaction between bitumen and water. This phenomenon causes the separation of bitumen from the aggregate surface or failure in the bitumen membrane $[2,3]$.

The loss of adhesion is shown in Fig. 1 as the stages of separation of bitumen from the aggregate due to the presence of water. In this figure, a drop of bitumen is in contact with the aggregate surface, which is immersed in water (Fig. 1(a)). As time passes, the contact angle $(\theta)$ between the two materials (asphalt and aggregate) in the presence of water increases (Fig. 1(b)). This process continues until the contact angle becomes large enough that the bitumen loses its contact with the aggregate (Fig. 1(c)) [4].

Aggregates with a high carbon content (hydrophobic or alkali), such as limestone, are covered easier. This type of aggregates contrary to aggregates with a high percentage of silica (hydrophilic or acid), constitutes a stronger connection with bitumen. One of the conventional methods to
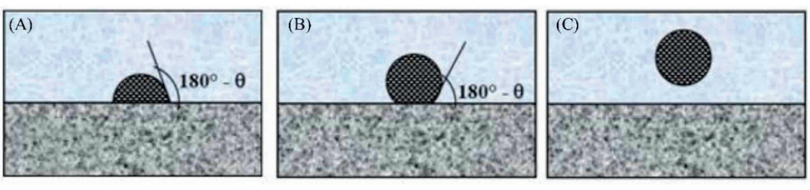

Fig. 1 The schematic figure for stages of separation of bitumen from the aggregate as a result of the presence of water [4] 
improve the moisture resistance is coating materials with hydrophobic properties such as hydrated lime. In addition to improve the resistance of asphalt mixtures against the moisture damage, it does not have a negative impact on the asphalt mixtures [5].

The resistance parameter ratio in wet to dry conditions is a common parameter to determine the moisture sensitivity of asphalt mixtures [6]. According to previous researches, the best test available with most compatible field results is the Lottman modified method according to AASHTO T283 [1]. Despite the proper accuracy, this method does not focus on measurements of fundamental characteristics of materials. The indicator represents the resistance of asphalt mixtures against the several various mechanisms of damage in a number without interpretation. It cannot be said that what contributes to the asphalt mixture's resistance against moisture so that the pavement design engineer could redesign the asphalt mixture based on those results $[7,8]$. Therefore, in recent years, researchers have tried to offer methods based on the fundamental properties of asphalt mixtures. This can be very useful in the new pavement design methods and considering the effect of additives [9].

The need for a method to quantify bitumen-aggregate-water adhesion based on the fundamental properties of materials is essential. This paper tries to evaluate the effects of modifying aggregates surface using thermodynamic concepts. The thermodynamic concepts can lead to the development of moisture damage prediction methods in addition to a series of new and efficient concepts to predict the moisture damage in asphalt mixtures. These methods, unlike mechanical experiments, take the damage mechanisms based on the properties of formed materials into consideration and state the reason of poor moisture resistance of asphalt mixtures.

\subsection{Literature review}

Bitumen and aggregate surface free energy (SFE) measurement can lead to a model that can predict moisture damage in asphalt mixtures [10]. Bitumen-aggregate adhesion system in dry and wet conditions was calculated in a study using the SFE theory and by measuring the SFE components of bitumen, aggregate, and water [11]. In another study, it was observed that the chemical and physical relationship between bitumen and aggregate is essential in measuring the moisture resistance of mixture [12]. In a study conducted on the use of SFE, measuring its components and its application in the pavement industry, it was shown that SFE concepts could help choose the most compatible bitumen-aggregate system based on their adhesion and resistance to moisture damage [13]. Hefer and Little [14] examined the role of different components of the SFE in determining moisture sensitivity and hence, could make a difference between different mixtures in terms of performance in wet conditions.

Limited studies evaluated the use of anti-stripping additives on the moisture sensitivity of asphalt mixtures using thermodynamic concepts [4]. Arabani and Hamedi [15] investigated the role of aggregates surface polymer coating to reduce the moisture damage of asphalt mixtures using SFE and dynamic modulus. They determined the continuity free energy of bitumen and bitumen-aggregate adhesion free energy (AFE) by measuring the SFE components of bitumen and aggregate. The results of the SFE method showed a good correlation with the results of laboratory tests. They also investigated an indicator for determining moisture sensitivity by the SFE method and their repetitive loading. The results showed that the use of liquid anti-stripping additives increased the total SFE of bitumen and reduced the stripping of bitumen from the aggregate surface in the presence of water [16]. Khodaii et al. [17] examined the influence of Zycosil on the sensitivity of asphalt mixtures. The results of the SFE method indicated that the use of this coating could reduce the acidic properties of aggregates and improve the bitumen-aggregate adhesion. Furthermore, some experiments are conducted using polymers and nanoparticles to investigate asphalt pavement's moisture properties $[16,18]$.

\subsection{The SFE theory}

The acid-base theory is one of the common methods to explain the SFE of materials based on their molecular structure [19]. According to this theory, the total SFE of each substance based on forces of surface molecules is divided into three components including the non-polar the Lifshitz-van der Waals (LW) component, the Lewis acid component, and the Lewis base component. The total SFE can be obtained as follows:

$\Gamma=\Gamma^{L W}+\Gamma^{A B}$,

where $\Gamma$ is the SFE of the material, $\Gamma^{L W}$ is the non-polar component of SFE, $\Gamma^{A B}$ is the polar component of SFE, $\Gamma^{+}$ is the acid component, and $\Gamma^{-}$is the base component. The acid-base component is formed from the Lewis acid and the Lewis base parameters.

$\Gamma^{A B}=2 \sqrt{\Gamma^{+} \Gamma^{-}}$ 
From the perspective of thermodynamics, cohesion free energy $\Delta G_{i}^{c}$ is defined as the amount of energy needed to create a crack at the unit level within a material. According to the SFE, it is easy to show the total work of continuity for various materials as follows:

$W^{A C}=2 \Gamma^{A}$.

That $\Gamma^{A}$ is the total SFE of the desired material. Continuity of bitumen is an important parameter used in some of the fundamental equations of failure mechanics to determine the energy required for the growth of very tiny cracks in the mastic phase of bituminous mixtures.

The AFE $\left(\Delta G^{c}\right)$, as previously defined, has two main components: Polar or acid-base components and non-polar or Lifshitz-Van der Waals components. Eq. (4) is used to determine the AFE between bitumen and aggregates.

$$
\begin{aligned}
\Delta G_{i}^{a} & =\Delta G_{i}^{a L W}+\Delta G_{i}^{a A B}= \\
& =2\left[\left(\sqrt{\Gamma_{S}^{l w} \Gamma_{l}^{l w}}\right)+\left(\sqrt{\Gamma_{S}^{+} \Gamma_{l}^{-}}\right)+\left(\sqrt{\Gamma_{S}^{-} \Gamma_{l}^{+}}\right)\right]
\end{aligned}
$$

Where $\Delta G_{i}^{a}$ is the AFE, $\varnothing G_{i}^{a L W}$ a non-polar component of AFE, $\varnothing G_{i}^{a A B}$ is the polar component of AFE, $\Gamma_{l}^{+}, \Gamma_{l}^{-}$ and $\Gamma_{l}^{l w}$ are the SFE components of bitumen, and $\Gamma_{S}^{+}, \Gamma_{S}{ }^{-}$ and $\Gamma_{S}^{l_{w}}$ are the SFE component of aggregates. For a mixture of bitumen and aggregates, Eq. (4) is used to measure the SFE components of bitumen and aggregates. Eq. (5) is used to calculate the adhesion of bitumen and aggregates in the presence of water. indexes 1,2 , and 3 represent the bitumen, aggregate, and water, respectively. If the AFE values are negative, the two materials tend to adhere to each other. This tendency increases as the value become more negative.

$$
\begin{aligned}
\Delta G_{132}^{a}= & \Gamma_{12}-\Gamma_{13}-\Gamma_{23}= \\
& -\left[\begin{array}{c}
\left(2 \Gamma_{3}^{L W}\right)+\left(4 \sqrt{\Gamma_{3}^{+} \Gamma_{3}^{-}}\right)-\left(2 \sqrt{\Gamma_{1}^{L W} \Gamma_{3}^{L W}}\right) \\
-\left(2 \sqrt{\Gamma_{3}^{+} \Gamma_{1}^{-}}\right)-\left(2 \sqrt{\Gamma_{1}^{+} \Gamma_{3}^{-}}\right)-\left(2 \sqrt{\Gamma_{2}^{L W} \Gamma_{3}^{L W}}\right) \\
-\left(2 \sqrt{\Gamma_{3}^{+} \Gamma_{2}^{-}}\right)-\left(2 \sqrt{\Gamma_{2}^{+} \Gamma_{3}^{-}}\right)+\left(2 \sqrt{\Gamma_{1}^{L W} \Gamma_{2}^{L W}}\right) \\
+\left(2 \sqrt{\Gamma_{1}^{+} \Gamma_{2}^{-}}\right)+\left(2 \sqrt{\Gamma_{2}^{+} \Gamma_{2}^{-}}\right)
\end{array}\right]
\end{aligned}
$$

\subsection{Statement and objectives}

This study aimed to discuss the impact of aggregate surface coatings on the moisture sensitivity of asphalt mixtures using the SFE concepts and dynamic modulus test in dry and wet conditions. The most important objectives of this study include:
- Measure and compare the SFE components of the base and modified aggregates

- Investigate the effects of aggregate surface modifiers on the bitumen-aggregate AFE and system separation energy

- Investigate the effects of anti-stripping additives on the moisture sensitivity of asphalt mixtures using the wet/dry dynamic modulus ratio

- Compare the results of SFE methods and dynamic modulus in wet and dry conditions

- Calculate the stripping process of asphalt mixtures by combining the results of the SFE method and the dynamic modulus

\section{Materials}

\subsection{Aggregate}

Limestone and granite aggregates with different hydrophilicity degrees are used in this study. Physical characteristics and mineralogical structures of the aggregates are presented in Table 1.

The granulation of the aggregates (Table 2) is the intermediate range of the ASTM for the production of dense asphalt mixtures.

\subsection{Bitumen}

The characteristics of the 60-70 bitumen prepared from the Isfahan refinery are provided in Table 3.

\subsection{Anti-stripping additives}

Two types of mineral additives namely potassium methyl silicate (PMS) and silane-siloxane (SS), are used as anti-stripping materials to modify the surface properties of aggregates and create better adhesion with the bitumen.

Both materials are used in the construction industry for waterproofing. PMS is used to waterproof surfaces such as concrete, brick, and plaster. Silicate reacts with carbon dioxide in the air and forms a water-resistant and insoluble coating within 24 hours. SS is a polar material that can penetrate the pores of the surface after dissolving in water and can create a hydrophobic layer on the surface. It is useful for surfaces that are directly exposed to environmental conditions such as rainfall.

\section{Design and test description}

Aggregates are initially divided into two categories of base and modified aggregates in which the aggregate surface is amended using the hydrophobic coatings. The SFE components of bitumen and base and modified aggregates 
Table 1 Physical and mineralogical characteristics of the aggregates used in this study

\begin{tabular}{|c|c|c|c|c|}
\hline Properties & Standard & Limestone & Granite & Specification limit \\
\hline \multicolumn{5}{|l|}{ Coarse aggregate } \\
\hline Bulk specific gravity $\left(\mathrm{g} / \mathrm{cm}^{3}\right)$ & ASTM C 127 & 2.63 & 2.61 & - \\
\hline SSD specific gravity $\left(\mathrm{g} / \mathrm{cm}^{3}\right)$ & & 2.65 & 2.63 & - \\
\hline Apparent specific gravity $\left(\mathrm{g} / \mathrm{cm}^{3}\right)$ & & 2.68 & 2.67 & - \\
\hline \multicolumn{5}{|l|}{ Fine aggregate } \\
\hline Bulk specific gravity $\left(\mathrm{g} / \mathrm{cm}^{3}\right)$ & ASTM C 128 & 2.62 & 2.60 & - \\
\hline SSD specific gravity $\left(\mathrm{g} / \mathrm{cm}^{3}\right)$ & & 2.65 & 2.62 & - \\
\hline Apparent specific gravity $\left(\mathrm{g} / \mathrm{cm}^{3}\right)$ & & 2.68 & 2.65 & - \\
\hline Specific gravity of filler $\left(\mathrm{g} / \mathrm{cm}^{3}\right)$ & ASTM D 854 & 2.65 & 2.65 & - \\
\hline Los Angeles abrasion (\%) & ASTM C 131 & 32 & 22 & $\operatorname{Max} 45$ \\
\hline Flat and elongated particles (\%) & ASTM D 4791 & 9 & 6 & $\operatorname{Max} 10$ \\
\hline Sodium sulfate soundness (\%) & ASTM C 88 & 7 & 9 & $\operatorname{Max} 10-20$ \\
\hline Fine aggregate angularity & ASTM C 1252 & 56.2 & 59.2 & $\operatorname{Min} 40$ \\
\hline \multicolumn{5}{|l|}{ mineralogical characteristics } \\
\hline $\mathrm{pH}$ & - & 7.8 & 6.7 & - \\
\hline $\mathrm{SiO}_{2}(\%)$ & - & 18.6 & 62.9 & - \\
\hline $\mathrm{Al}_{2} \mathrm{O}_{3}(\%)$ & - & 3.2 & 13.4 & - \\
\hline $\mathrm{Fe}_{2} \mathrm{O}_{3}(\%)$ & - & 4.7 & 2.3 & - \\
\hline $\operatorname{MgO}(\%)$ & - & 1.4 & 0.8 & - \\
\hline $\mathrm{CaO}(\%)$ & - & 61.9 & 3.1 & - \\
\hline
\end{tabular}

Table 2 Gradation of aggregates used in the study

\begin{tabular}{cccccccc}
\hline Sieve $(\mathrm{mm})$ & 37.5 & 25 & 12.5 & 4.75 & 2.36 & 0.3 & 0.075 \\
\hline $\begin{array}{c}\text { Lower- } \\
\text { upper limits }\end{array}$ & 100 & $90-100$ & $56-80$ & $29-59$ & $19-45$ & $5-17$ & $1-7$ \\
Passing (\%) & 100 & 95 & 68 & 44 & 32 & 11 & 4 \\
\hline
\end{tabular}

Table 3 Characteristics of base bitumen used in this study

\begin{tabular}{|c|c|c|c|}
\hline Test method & Specification & Test results & \\
\hline \multicolumn{2}{|c|}{ Flash point AASHTO T48 } & $230^{\circ} \mathrm{C}$ & 295 \\
\hline \multicolumn{2}{|c|}{ Rotational viscosity@135 ${ }^{\circ} \mathrm{C}$} & 3.0 & 0.32 \\
\hline \multicolumn{2}{|c|}{ Test temperature ${ }^{\circ} \mathrm{C}$} & Min 1.00 & $\mathrm{G}^{*} / \sin \delta$ \\
\hline \multicolumn{2}{|c|}{$64^{\circ} \mathrm{C}$} & $\mathrm{kPa}$ & $3.1 \mathrm{kPa}$ \\
\hline \multicolumn{2}{|c|}{ Test temperature ${ }^{\circ} \mathrm{C}$} & Max 5000 & $\mathrm{G}^{*} \cdot \sin \delta$ \\
\hline \multicolumn{2}{|c|}{$25^{\circ} \mathrm{C}$} & $\mathrm{kPa}$ & $2950 \mathrm{kPa}$ \\
\hline Test temperature ${ }^{\circ} \mathrm{C}$ & Stiffness MPa & $147 \mathrm{Mpa}$ & Max $300 \mathrm{MPa}$ \\
\hline$-22{ }^{\circ} \mathrm{C}$ & m-value & 0.3299 & Min 0.30 \\
\hline
\end{tabular}

are measured using the Wilhelmy plate and the universal Absorption machine. Then, mix design is carried out to determine the optimum bitumen content (OBC) of samples. In addition, the dynamic modulus test in dry and wet conditions is performed with three replicates to determine the moisture sensitivity of the asphalt mixtures. Finally, the stripping process is discussed by combining the results of the SFE and the dynamic modulus.

\subsection{Aggregate surface modification with anti-stripping materials}

To improve the surface of the aggregates, the slurry of anti-stripping materials and water is provided. The mass mixing ratios of water and anti-stripping materials for additives PMS and SS were 1:4 and 1:8, respectively. A mixer at $200 \mathrm{rpm}$ for 3 minutes was used to dissolve the anti-striping materials in the water and prepare the slurry. Then, the aggregates remain on the sieve of $2.36 \mathrm{~mm}$ were immersed in the slurry and brought out after 2 minutes. The coated aggregates were spread on the surface of a steel mesh container for 1 hour to drain the preliminary moisture content. Finally, the aggregates were put in the oven at a temperature of $110^{\circ} \mathrm{C}$ for 24 hours. After the evaporation of moisture, the volume of additives absorbed on the surface of the aggregates were obtained.

\subsection{Mix design}

The Marshall mix design method was applied based on ASTM D1559 to determine the OBC. Since the coating on the surface of aggregates causes a change in the bitumen absorption, mix design for the samples made with base and modified aggregates was done individually. 


\subsection{The dynamic modulus test}

\subsubsection{Preparation of samples}

The AASHTO T283 is used to build the samples and put them under conditions. For each compound, six samples were made: three samples for dry condition and three samples for wet condition tests.

The samples were compressed to achieve the desired air content. After condensation, their diameter, height, real and maximum gravity, and air voids were measured. Then, half of the samples in each group remained in dry conditions, and the three other samples were kept under wet conditions. To put the samples under these conditions, they were initially saturated by relative vacuum conditions (13-67 kPa) for five minutes. Then, while submerged, they were held without vacuum conditions for 5-10 minutes until their saturation reach to $70-80$ percent. The samples were kept in the freezer at $-18{ }^{\circ} \mathrm{C}$ for 16 hours. Then, they were put in a hot water bath at $60{ }^{\circ} \mathrm{C}$ for 24 hours and finally reached to room temperature $\left(25^{\circ} \mathrm{C}\right)$.

\subsubsection{Process of loading}

The dynamic modulus test was carried at $25{ }^{\circ} \mathrm{C}$ with a loading frequency of $1 \mathrm{~Hz}$ with a stress level of $200 \mathrm{MPa}$. The dynamic modulus values were obtained using the maximum amount of stress and strain in each cycle. The dynamic modulus for each mixture in a particular loading cycle is measured using Eq. (6). where, is the maximum value of stress for a specific cycle and is the corresponding value of strain in the same cycle.

$E^{*}=\frac{\sigma_{\max }}{\varepsilon_{\max }}$

After determining the dynamic modulus in wet and dry conditions, the modulus ratio, which is considered to be an indicator for moisture sensitivity in asphalt mixtures, were obtained for each cycle according to Eq. (7). The higher the $K$ parameter, the more resistant is the asphalt mixture under the simultaneous effect of traffic and moisture.

$$
K=\frac{E_{w e t}^{*}}{E_{d r y}^{*}} \times 100
$$

Where, $E_{w e t}^{*}$ and $E_{d r y}^{*}$ represent the values of dynamic modulus in wet and dry conditions, respectively.

\subsection{Measuring the SFE components}

The aggregate and bitumen SFE has been measured using the Universal Sorption Device (USD) and the Wilhelmy plate method, respectively, which was developed by Bhasin and Little [20] and Hefer et al. [21].

\subsubsection{Measuring the SFE components of the base and modified aggregates}

The USD indirectly determines the aggregate SFE using gas adsorption by three solvents. At first, the aggregates were dried and sieved. After washing in the wash cycle, the aggregates were kept in the oven for 4 hours. The dried aggregates were brought to room temperature and placed in a desiccator. Upon cooling, the materials were placed in USD using the aluminum grille holder. Three research materials with specified SFE components (Table 4), were required to create a set of three equations and three unknowns and get the SFE components of a solid body.

For each of the liquids, Eq. (8) must be satisfied.

$$
\begin{aligned}
W_{S, V}^{a} & =\pi_{e}+2 \Gamma_{v}^{\text {total }}= \\
& -2\left[\sqrt{\Gamma_{s}^{L W} \Gamma_{l}^{L W}}+\sqrt{\Gamma_{s}^{+} \Gamma_{l}^{-}+} \sqrt{\Gamma_{s}^{-} \Gamma_{l}^{+}}\right]
\end{aligned}
$$

In this equation, $W_{S, V}^{a}$ is the work of adhesion between the aggregate surface $(s)$ and vapor $(v), \Gamma_{v}^{\text {total }}$ is the SFE for the total vapor of the research material, and $\pi_{e}$ is the equilibrium distribution pressure related to the vapor of research material on the aggregate surface. Equilibrium distribution pressure related to the vapor on the aggregate surface by isothermal adsorption is obtained using Eq. (9).

$\pi_{e}=\frac{R T}{M A} \int_{0}^{P_{n}} \frac{n}{p} d p$

In this equation, $R$ is the universal gas constant, $T$ is the test temperature, $M$ is the molecular weight of the research material vapor, $n$ is the mass of vapor adsorbed per unit mass of the aggregate in the vapor pressure $p$, and $A$ is the specific surface area of the aggregate.

The specific surface area of aggregates through the BET classic relationship is obtained using the Eq. (10).

$A=\left(\frac{n_{m} \times N_{0}}{M}\right) \times \alpha$

Table 4 SFE components of research materials to measure the SFE components of aggregates $\left(\mathrm{ergs} / \mathrm{cm}^{2}\right)$

\begin{tabular}{lccccc}
\hline \multicolumn{5}{c}{ SFE } & \multicolumn{5}{c}{ SFE components $\left(\mathrm{ergs} / \mathrm{cm}^{2}\right)$} \\
components & $\begin{array}{c}\text { Total } \\
\text { SFE }\end{array}$ & $\begin{array}{c}\text { Lifshitz } \\
\text { Van der } \\
\text { Waals }\end{array}$ & $\begin{array}{c}\text { Acid- } \\
\text { Base }\end{array}$ & Acidic & Alkaline \\
\hline n-Hexane & 18.4 & 18.4 & 0 & 0 & 0 \\
$\begin{array}{l}\text { Methyl Propyl } \\
\text { Ketone (MPK) }\end{array}$ & 24.7 & 24.7 & 0 & 0 & 19.6 \\
Water & 72.8 & 21.8 & 51 & 25.5 & 25.5 \\
\hline
\end{tabular}


In this equation, $N_{0}$ is Avogadro's number, $\alpha$ is the image surface of a molecule, $n_{m}$ single-layer absorbent capacity onto the surface of the aggregate. The number of molecules needed to cover the aggregate surface in a layer called "single-layer absorbent capacity onto the surface of aggregate" is obtained by Eq. (11). In this equation, $S$ and $I$ are the slope and length of the source graph, which shows $p / n\left(p_{0}-p\right)$ versus $p / p_{0}$, respectively. Where $p, p_{0}$ and $n$ are the partial vapor pressure, the maximum saturation vapor pressure, and the mass of vapor adsorbed on the mass of aggregate units, respectively.

$n_{m}=\frac{1}{S+I}$

Eq. (12) is used to calculate the non-polar components of SFE using a non-polar solvent:

$\Gamma_{2}^{L W}=\frac{\left(\pi_{e}+2 \Gamma_{1}\right)^{2}}{4 \Gamma_{1}^{L W}}$.

A monopolar liquid $(m)$ and a bipolar liquid $(b)$ are used to determine the acid-base components.

$\Gamma_{2}^{+}=\frac{\left[\pi_{e}+2 \Gamma_{1 m}-\left(\Gamma_{2}^{L W} \Gamma_{1 m}^{L W}\right)\right]}{2 \Gamma_{1 m}^{-}}$

$\Gamma_{2}^{+}=\frac{\left[\pi_{e}+2 \Gamma_{1 b}-2\left(\Gamma_{2}^{L W} \Gamma_{1 b}^{L W}\right)-2\left(\Gamma_{2}^{+} \Gamma_{1 b}^{L W}\right)\right]^{2}}{4 \Gamma_{1 b}^{+}}$

The total SFE of the aggregate is obtained by Eq. (15):

$\Gamma=\Gamma_{2}^{L W}+2\left(\Gamma_{2}^{+} \Gamma_{2}^{-}\right)$.

\subsubsection{Measuring the bitumen SFE components}

The contact angle between bitumen and liquid were obtained using the Wilhelmy plate. When a plate is suspended in the air, Eq. (16) is used to determine the force required to keep it in balance.

$F=W t_{\text {plate }}+W t_{\text {asphalt }}-V \cdot \rho_{\text {air }} . g$,

where $P_{t}$ is the force required to hold the plate, $W t_{\text {plate }}$ is the weight of the metal plate, $W t_{\text {asphalt }}$ is the weight of asphalt, $V$ is the volume of bitumen film, $g$ is the local gravity acceleration, and $\rho$ is the density of air.

When the plate impregnated with bitumen is immersed in a liquid, Eq. (16) becomes:

$$
\begin{gathered}
F=W t_{\text {plate }}+W t_{\text {asphalt }}+P_{t} \Gamma_{L} \cos \theta \\
-V_{\text {im }} \cdot \rho_{L} \cdot g-\left(V-V_{\text {im }}\right) \cdot \rho_{\text {air }},
\end{gathered}
$$

where $P_{t}$ is the Perimeter of the plate impregnated with bitumen, $\Gamma_{L}$ is the total SFE of liquid, $\theta$ is the dynamic contact angle between the bitumen and liquid, $V_{i m}$ is the volume of the immersed part of the plate impregnated with bitumen, $V$ is the total volume of the bitumen film and $\rho_{L}$ is the density of liquid. By combining the above two equations, the Eq. (18) can be obtained:

$\Delta F=P_{t} \Gamma_{L} \cos \theta-V_{\text {im }} \cdot \rho_{L} \cdot g+V_{\text {im }} \cdot \rho_{\text {air }} \cdot g$.

By re-writing the above Equation in terms of the unknown contact angle, and using the Wilhelmy plate:

$\cos \theta=\frac{\left(\Delta F+V_{i m} \cdot\left(\rho_{L}-\rho_{\text {air }}\right) \cdot g\right)}{P_{t} \Gamma_{L}}$.

The Good-Van Oss-Chaudhury Equation is used to connect angle and SFE components:

$$
\begin{aligned}
\Gamma_{L 1}(1+\cos \theta) & =2\left[\left(\Gamma_{L i}^{L W} \Gamma_{2}^{L W}\right)^{0.5}+\left(\Gamma_{L i}^{-} \Gamma_{2}^{+}\right)^{0.5}\right. \\
& \left.+\left(\Gamma_{L i}^{+} \Gamma_{2}^{-}\right)^{0.5}\right] .
\end{aligned}
$$

To get the passive components, at least three liquids with precise SFE components are required. Water, glycerol, and formamide, which their SFE components are given in Table 5 were used to this purpose.

\subsection{The combination of dynamic modulus test and SFE}

Damage prediction in Schapery's theory can be validated based on the repetitive loading tests theory. Moisture damage of asphalt mixtures can be understood by calculating the percentage of the aggregate surface that experienced stripping in different loading cycles. The ratio of stiffness modulus in dry to wet conditions can be same as the ratio of bitumen-aggregate adhesion in dry and wet conditions. This concept is shown in Eq. (21).

$$
\frac{E^{*}{ }_{\text {wet }}}{E^{*}{ }_{d r y}}=\frac{\left[\Delta G_{12} *(1-P)+\Delta G_{132} P\right]}{\left[\Delta G_{12}\right]}
$$

Table 5 The SFE components of research materials to measure the bitumen SFE components (ergs/ $\left./ \mathrm{cm}^{2}\right)$

\begin{tabular}{cccccc}
\hline \multicolumn{5}{c}{ SFE components } \\
$\begin{array}{ccccc}\text { SFE } \\
\text { components }\end{array}$ & Total SFE & $\begin{array}{c}\text { Lifshitz } \\
\text { Van der } \\
\text { Waals }\end{array}$ & Acid-Base & Acidic & Alkaline \\
\hline Water & 72.6 & 21.6 & 51 & 25.5 & 25.5 \\
Glycerol & 62.8 & 34 & 28.8 & 3.92 & 57.4 \\
Formamide & 58 & 39 & 19 & 2.28 & 39.6 \\
\hline
\end{tabular}


Where $\Delta G_{12}$ is the bitumen-aggregate adhesion energy, $\Delta G_{132}$ is the separation energy or bitumen-aggregate energy of the system in a saturated condition, and $P$ is the percent of the aggregate surface that experienced stripping.

Eq. (21) can be converted to Eq. (22) to test the straincontrolled repetitive loading. All parameters of Eq. (22) except $\mathrm{P}$ index can be obtained from thermodynamic concepts with the help of the bitumen-aggregates SFE components measurement and dynamic modulus testing.

$$
\frac{E_{\text {wet }}^{*}}{E_{d r y}^{*}}=\frac{\left(\frac{\sigma}{\varepsilon}\right)_{\text {wet }}}{\left(\frac{\sigma}{\varepsilon}\right)_{d r y}}=\frac{\varepsilon_{\text {wet }}}{\varepsilon_{d r y}}=\frac{\left[\Delta G_{12}(1-P)+\Delta G_{132} P\right]}{\left[\Delta G_{12}\right]}
$$

\section{Results}

\subsection{Aggregate surface coating}

Table 6 expresses the mass ratio of coating absorbed on the surface to the initial mass of aggregates. Data shows that higher amounts of SS coating have been absorbed on the aggregate surface. This phenomenon can be attributed to the polarity of this material and its better interaction with aggregates which have polar properties. Furthermore, it is observed that the percentage of coating absorbed on the surface of limestone aggregates is more than granite aggregates. The main reason for this occurrence is the porous structure of limestone aggregates compared to granite aggregates.

\subsection{Mix design}

Results of mix design related to different types of asphalt mixtures are presented in Table 7. As is evident, the use of a coating on the aggregate surface has reduced the OBC. The main reason for this occurrence is the decrease in the surface pores which causes the bitumen to effectively adhere to the aggregates. Moreover, the results presented in this table show that samples made with limestone aggregates have a higher OBC compared to those made with granite aggregates. This is due to the surface pores of

Table 6 The amount of coating formed on the surface of aggregates (\%)

\begin{tabular}{lcc}
\hline Aggregate & PMS & SS \\
\hline Limestone & 3.1 & 3.8 \\
Granite & 2.1 & 2.4 \\
\hline
\end{tabular}

Table 7 The OBC for different samples of asphalt mixtures (\%)

\begin{tabular}{lccl}
\hline Aggregate & Uncoated & PMS & SS \\
\hline Limestone & 5.8 & 5.4 & 5.3 \\
Granite & 5.5 & 5.3 & 5.3 \\
\hline
\end{tabular}

limestone aggregates, which ineffectively absorbs higher amounts of bitumen compared to granite aggregates. In samples made with modified aggregates, the OBC for both types of aggregates are close to each other.

\subsection{SFE components of materials}

\subsubsection{SFE components of bitumen}

The SFE components of bitumen are presented in Table 8. It is obvious that the acidic SFE component of bitumen is higher than its alkaline component. This makes the adhesion of the bitumen with relatively acidic properties to acidic aggregates such as granite and quartzite to be eliminated by the presence of water and thus lead to stripping. It is also clear that the nonpolar component of bitumen is greater than its polar component and, bitumen is considered to be a substance with low polarity. The significant links between bitumen and aggregates that are not broken in the presence of water are related to the adhesion between the non-polar components of bitumen and aggregates. These links will remain stable in the presence of water, but the links formed between the polar SFE components of aggregates and bitumen have a higher potential to break in the presence of water.

\subsubsection{SFE components of aggregates}

The results of measuring the SFE components of the aggregates presented in Table 9 show that aggregates generally have higher alkaline components compared to acidic components. Similar results were observed in previous studies about acidic aggregates [22].

Table 8 The bitumen SFE components

\begin{tabular}{lccccc}
\hline \multirow{8}{*}{ Bitumen } & \multicolumn{5}{c}{ Surface Free Energy components $\left(\mathrm{ergs} / \mathrm{cm}^{2}\right)$} \\
& Total SFE & $\begin{array}{l}\text { Lifshitz } \\
\text { Van der } \\
\text { Waals }\end{array}$ & Acid-Base & Acidic & Alkaline \\
Result & 15.89 & 13.69 & 2.20 & 2.58 & 0.47 \\
\hline
\end{tabular}

Table 9 SFE components of the base and modified aggregates SFE components (ergs $\left./ \mathrm{cm}^{2}\right)$

\begin{tabular}{lccccc} 
Aggregate type & Alkaline & Acidic & $\begin{array}{c}\text { Acid- } \\
\text { Base }\end{array}$ & $\begin{array}{c}\text { Lifshitz } \\
\text { Van der } \\
\text { Waals }\end{array}$ & $\begin{array}{l}\text { Total } \\
\text { SFE }\end{array}$ \\
\hline Granite & 522.4 & 31.7 & 257.5 & 67.1 & 324.6 \\
Granite + PMS & 502.3 & 25.1 & 224.5 & 73.4 & 297.9 \\
Granite + SS & 525.3 & 29.4 & 248.6 & 65.8 & 314.4 \\
Limestone & 525.8 & 20.5 & 207.7 & 68.8 & 276.6 \\
Limestone + PMS & 506.9 & 19.3 & 197.7 & 80.5 & 278.2 \\
Limestone + SS & 531.2 & 19.2 & 202.0 & 65.2 & 267.2 \\
\hline
\end{tabular}


The results show that the use of PMS coating, which is a non-polar material, causes the acidic and alkaline components of both types of aggregates to be reduced. Furthermore, SS coating, which is a polar substance with alkaline characteristics, has caused the acidic component of the SFE for both types of granite and limestone aggregates to be reduced. Inversely, the SS coating increases the alkaline components of the aggregate SFE. This increases the alkaline properties of the aggregates modified with SS which increases its adhesion to bitumen, as a relatively acidic material. Based on Table 9, it is observed that the use of PMS as a non-polar substance increased the non-polar components of SFE for both types of aggregates. In reverse, the use of SS reduced the non-polar components of the aggregate SFE slightly.

The results of total SFE are not very important, because moisture damage occurs in bitumen membranes or on the bitumen-aggregate contact surface. In fact, the total SFE of aggregates is vital in determining the amount of energy needed to create a rupture in the aggregate structure often ignored in disruptions caused by the influence of moisture.

\subsubsection{The AFE}

The adhesion between different materials in dry and wet conditions are presented in Table 10. The bitumen-aggregate AFEs in dry conditions indicate that the use of PMS improved the aggregate-bitumen adhesion in all samples. This phenomenon can be due to the improvement of the non-polar properties of the aggregates and formation of better nonpolar links between them and non-polar bitumen. The use of SS in both types of aggregates has led to a decline in the bitumen-aggregate adhesion. Increment or reduction of the AFE is essential only in dry conditions and is not a criterion to improve or weaken the moisture performance of asphalt mixtures. Due to the constancy of the bitumen, results of the bitumen-water AFE are the same for all samples. Data indicate that both coatings have reduced the desire for hydrophilicity in aggregates and, acidic aggregates have the higher AFE and a greater desire for hydrophilicity compared to the granite aggregates. The bitumen-aggregates AFE in wet conditions (separation energy) is the most crucial parameter to determine stripping tendency in asphalt mixtures. The use of both types of coatings on the surface of aggregates has caused the value of this parameter to be close to zero. This means that the system is in a more thermodynamically stable condition, and the probability of stripping has decreased.

\subsection{Dynamic modulus ratio}

The dynamic modulus ratios in wet and dry conditions ( $\mathrm{K}$ index), as an indicator to determine the moisture susceptibility of asphalt mixtures, for samples made with limestone and granite aggregates are shown in Figs. 2 and 3, respectively. Data presented in these figures show that the $\mathrm{K}$ index is always less than 100. This is expected because the effect

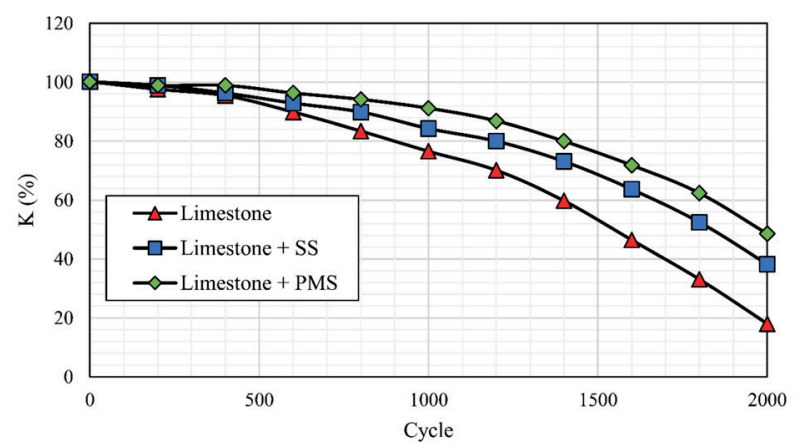

Fig. 2 The ratio of dynamic modules in samples made with limestone aggregates

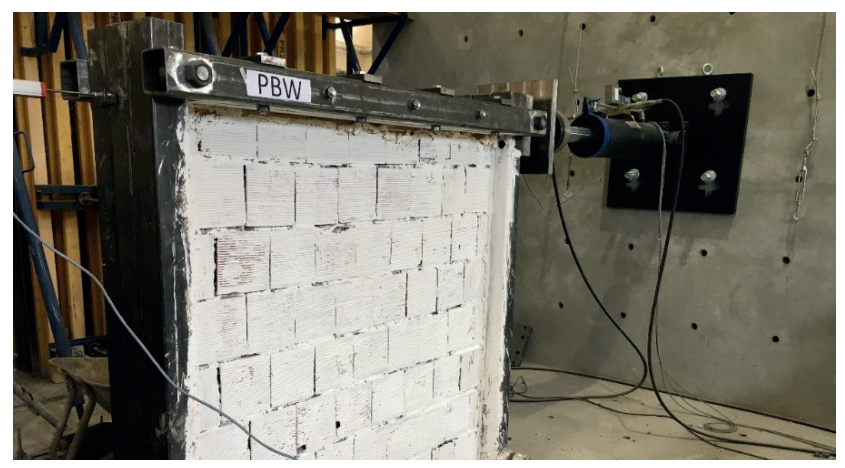

Fig. 3 The ratio of dynamic modulus in samples made with granite aggregates

Table 10 The SFE components of adhesion $\left(\mathrm{ergs} / \mathrm{cm}^{2}\right)$

\begin{tabular}{|c|c|c|c|c|c|}
\hline Aggregate & Bitumen & Asphalt-Aggregate & Asphalt-Water & Water-Aggregate & Asphalt-Aggregate in the presence of Water \\
\hline Granite & \multirow{6}{*}{ AC $60-70$} & 131.14 & 57.26 & 364.24 & -130.71 \\
\hline Granite + PMS & & 131.78 & 57.26 & 356.95 & -122.14 \\
\hline Granite + SS & & 130.33 & 57.26 & 362.01 & -129.43 \\
\hline Limestone & & 130.22 & 57.26 & 354.80 & -122.01 \\
\hline Limestone + PMS & & 134.06 & 57.26 & 353.50 & -117.72 \\
\hline Limestone $+\mathrm{SS}$ & & 128.61 & 57.26 & 352.46 & -121.65 \\
\hline
\end{tabular}


of water alters the properties of bitumen and decreases the adhesion in the bitumen-aggregate contact surface which reduces the modulus ratio of asphalt mixtures in wet conditions. Table 10 also shows that the bitumen-aggregate AFE in wet conditions is negative. This means that the system releases energy during the stripping process. Based on the thermodynamics concepts, the process that releases energy is spontaneous and occurs under any circumstances.

The results presented in Fig. 2 show that the use of the coatings on the surface of limestone aggregates has increased the $\mathrm{K}$ index. This means that the dynamic modulus loss in wet conditions has declined compared to the dry conditions. As a result of using water, the aggregate surface coating has reduced the amount of resistance loss in asphalt mixtures. The positive impact of the hydrophobic coating on asphalt mixtures has been evident in higher cycle numbers. As it can be seen, the PMS modified samples have a better performance compared to the control and the SS modified samples.

The $\mathrm{K}$ index in the samples made with granite aggregates is lesser compared to the samples made with acidic aggregates. Furthermore, it is observed that this index in the samples made with granite aggregates has a steeper downward trend compared to the samples made with limestone aggregates. This represents a faster reduction in the dynamic modulus in wet conditions for acidic aggregates. The use of aggregates surface coating improves the performance of asphalt mixtures made with granite aggregates. Similar to the limestone samples, PMS had a better performance compared to SS.

\subsection{Stripping process}

Figs. 4 and 5 show that the use of hydrophobic coatings on the surface of aggregates has reduced the stripping percentage of the aggregate surface in different loading cycles. This means that aggregate surface coating does not allow the moisture to penetrate the asphalt-aggregate contact surface, and increases the moisture resistance of asphalt mixtures. Moreover, results show that the granite samples have worse moisture resistance compared to the limestone samples. The stronger adhesion of basic aggregates with bitumen as an acidic substance can be the main reason for this occurrence.

It can be seen from the data presented in Figs. 4 and 5 that the slope of the stripping percentages against the loading cycles diagram has an increasing trend. In fact, almost all aggregates are bonded with bitumen in initial loading cycles. The more the samples are exposed to wet conditions

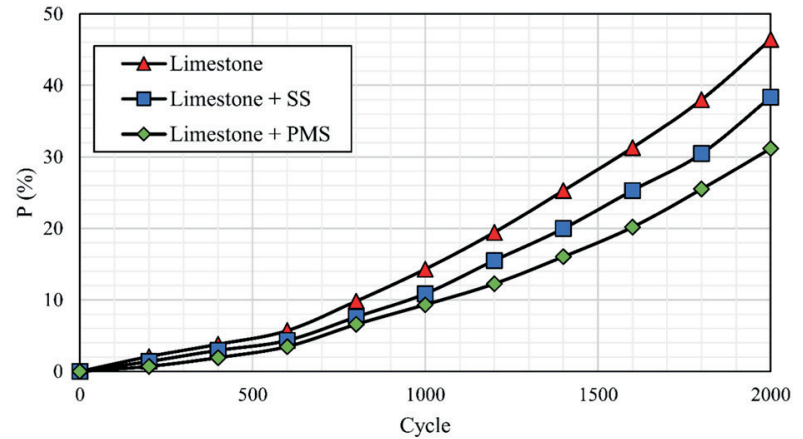

Fig. 4 Stripping percentage of aggregates surface in the samples made with limestone aggregates

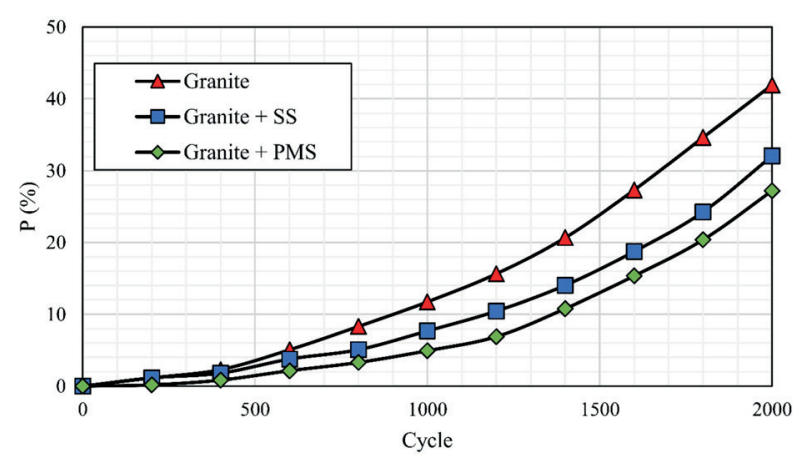

Fig. 5 Stripping percentage of aggregates surface in the samples made with granite aggregates

and repeated loading cycles, the higher the percentage of stripping occurs. This causes a decrease in adhesion, and with a reduction in the percentage of aggregates connected and intensifies each other makes the moisture damage process continues with a higher slope.

\section{Conclusions}

This study aimed to investigate the effects of aggregates surface hydrophobic coatings on the stripping of asphalt mixtures. The thermodynamic concepts and repetitive loading tests have been used to analyze the impact of the aggregate surface coating mechanism and study the performance of hydrophobic coatings in reducing the moisture damage of asphalt mixtures. The most important results obtained through this study include:

- The use of non-polar hydrophobic coats reduces the acidic and alkaline components of the SFE for both types of aggregates.

- In both types of aggregates, the polar hydrophobic coating causes the acidic and alkaline components of the SFE to decrease and increase, respectively.

- The non-polar coating materials increase the aggregates-bitumen AFE while the polar coating materials reduce it. 
- The use of both types of hydrophobic coatings on the aggregate surface causes a reduction in the water-aggregate AFE, which shows the amount of hydrophilicity tendency of aggregates. This decline is more evident in granite aggregates.

- Coating the aggregates with hydrophobic materials reduces the bitumen-aggregate AFE in wet conditions. This means that the released energy in the stripping process and thus the tendency of the system to strip is reduced.

- The wet/dry dynamic modulus ratio in the samples made with modified aggregates is higher. This indicates that the hydrophobic coating increases the

\section{References}

[1] Arabani, M., Tahami, S. A., Hamedi, G. H. "Performance evaluation of dry process crumb rubber-modified asphalt mixtures with nanomaterial", Road Materials and Pavement Design, 19(5), pp. 1241-1258, 2018.

https://doi.org/10.1080/14680629.2017.1302356

[2] Hamedi, G. H., Tahami, S. A. "The effect of using anti-stripping additives on moisture damage of hot mix asphalt", International Journal of Adhesion and Adhesives, 81, pp. 90-97, 2018. https://doi.org/10.1016/j.ijadhadh.2017.03.016

[3] Hamedi, G., Sohrabi, M., Sakanlou, F., Tahami, S. A. "Investigating the Effect of Various Fillers on Cohesive Failure Mechanism in Asphalt Mixtures", Periodica Polytechnica Civil Engineering, 64(1), pp. 144-155, 2020.

https://doi.org/10.3311/PPci.14505

[4] Hamedi, G. H., Azarhoosh, A. R., Khodadadi, M. "Effects of Asphalt Binder Modifying with Polypropylene on Moisture Susceptibility of Asphalt Mixtures with Thermodynamically Concepts", Periodica Polytechnica Civil Engineering, 62(4), pp. 901-910, 2018. https://doi.org/10.3311/PPci.11570

[5] Gorkem, C., Sengoz, B. "Predicting stripping and moisture induced damage of asphalt concrete prepared with polymer modified bitumen and hydrated lime", Construction and Building Materials, 23(6), pp. 2227-2236, 2009.

https://doi.org/10.1016/j.conbuildmat.2008.12.001

[6] Nejad, F. M., Abandansari, H. F. "Evaluating the Effects of Using Recycled Asphalt Pavements on Fatigue Properties of Warm Mix Asphalt", Periodica Polytechnica Civil Engineering, 61(3), pp. 454461, 2017.

https://doi.org/10.3311/PPci.8320

[7] Moghadas Nejad, F., Azarhoosh, A. R., Hamedi, G. H., Azarhoosh, M. J. "Characterization of permanent deformation resistance of precipitated calcium carbonate modified asphalt mixture", Journal of Civil Engineering and Management, 21(05), pp. 615-622, 2015. https://doi.org/10.3846/13923730.2014.890654

[8] Rahmani, H., Shirmohammadi, H., Hamedi, G. H. "Effect of Asphalt Binder Aging on Thermodynamic Parameters and Its Relationship with Moisture Sensitivity of Asphalt Mixes", Journal of Civil Engineering and Management, 30(11), pp. 258-269, 2018. https://doi.org/10.1061/(ASCE)MT.1943-5533.0002453 dynamic modulus of samples in the wet conditions more than the dry samples.

- The stripping percentage slope of the aggregate surface in loading cycles has an increasing trend. In fact, the reduction of the aggregate surface coated with bitumen and the damaging effects of moisture leads to the reduction of the stripping process in samples.

- The use of both types of coating materials on the aggregate surface reduces the stripping tendency of aggregates in different loading cycles.

- The use of hydrophobic coatings has a more evident impact on the samples made with acid aggregates, which are more susceptible to moisture damages.

[9] Tóth, Cs., Primusz, P. "New Hungarian Mechanistic-Empirical Design Procedure for Asphalt Pavements", The Baltic Journal of Road and Bridge Engineering, 15(1), pp. 161-186, 2020. https://doi.org/10.7250/bjrbe.2020-15.466

[10] Wasiuddin, N. M. "Effect of Additives on Surface Free Energy Characteristics of Aggregates and Binders in Hot Mix Asphalt", PhD Dissertation, University of Oklahoma, 2007. [online] Available at: https://shareok.org/handle/11244/1261

[10] Bhasin, A., Masad, E., Little, D., Lytton, R. "Limits on Adhesive Bond Energy for Improved Resistance of Hot-Mix Asphalt to Moisture Damage", Transportation Research Record: Journal of the Transportation Research Board, 1970(1), pp. 2-13, 2006. https://doi.org/10.1177/0361198106197000101

[12] Copeland, A. R. "Influence of moisture on bond strength of asphalt-aggregate systems", $\mathrm{PhD}$ Dissertation, Vanderbilt University, 2007. [online] Available at: https://etd.library.vanderbilt. edu//available/etd-08032007-061046/

[13] Cheng, D. "Surface free energy of asphalt-aggregate system and performance analysis of asphalt concrete based on surface free energy", PhD Dissertation, Texas A \& M University, 2003.

[14] Hefer, A., Little, D. "Adhesion in bitumen-aggregate systems and quantification of the effect of water on the adhesive bond", Texas A \& M University, College Station, TX, USA, Report No. ICAR/ 505-1, 2005. [online] Available at: https://repositories.lib.utexas. edu/handle/2152/35371

[15] Arabani, M., Hamedi, G. H. "Using the Surface Free Energy Method to Evaluate the Effects of Polymeric Aggregate Treatment on Moisture Damage in Hot-Mix Asphalt", Journal of Materials in Civil Engineering, 23(6), pp. 802-811, 2011. https://doi.org/10.1061/(ASCE)MT.1943-5533.0000228

[16] Hamedi, G. H. "Investigating the Use of Nano Coating Over the Aggregate Surface on Moisture Damage of Asphalt Mixtures", International Journal of Civil Engineering, 16, pp. 659-669, 2018. https://doi.org/10.1007/s40999-016-0143-x

[17] Khodaii, A., Khalifeh, V., Dehnad, M. H., Hamedi, G. H. "Evaluating the Effect of Zycosoil on Moisture Damage of Hot-Mix Asphalt Using the Surface Energy Method", Journal of Materials in Civil Engineering, 26(2), pp. 259-266, 2013. https://doi.org/10.1061/(ASCE)MT.1943-5533.0000819 
[18] Hamedi, G. H. "Effects of Polymeric Coating the Aggregate Surface on Reducing Moisture Sensitivity of Asphalt Mixtures", International Journal of Civil Engineering, 16, pp. 1097-1107, 2013. https://doi.org/10.1007/s40999-017-0263-y

[19] Van Oss, C. J., Chaudhury, M. K., Good, R. J. "Interfacial Lifshitzvan der Waals and polar interactions in macroscopic systems", Chemical Reviews, 88(6), pp. 927-941, 1988. https://doi.org/10.1021/cr00088a006

[20] Bhasin, A., Little, D. N. "Characterization of Aggregate Surface Energy Using the Universal Sorption Device", Journal of Materials in Civil Engineering, 19(8), pp. 634-641, 2007.

https://doi.org/10.1061/(ASCE)0899-1561(2007)19:8(634)
[21] Hefer, A. W., Bhasin, A. Little, D. N. "Bitumen Surface Energy Characterization Using a Contact Angle Approach", Journal of Materials in Civil Engineering, 18(6), pp. 759-767, 2006. https://doi.org/10.1061/(ASCE)0899-1561(2006)18:6(759)

[22] Hamedi, G. H., Moghadas Nejad, F. "Use of aggregate nanocoating to decrease moisture damage of hot mix asphalt", Road Materials and Pavement Design, 17(1), pp. 32-51, 2015.

https://doi.org/10.1080/14680629.2015.1056215 